\title{
A Cross-Sectional Assessment of Health Literacy among Hypertensive Community of Quetta City, Pakistan
}

\author{
Farrukh Shahzad ${ }^{1}$, Fahad Saleem ${ }^{1}$, Qaiser Iqbal ${ }^{1}$, Naheed Haque ${ }^{1}$, Sajjad Haider ${ }^{1}$, Muhammad Salman ${ }^{2}$, Imran \\ Masood $^{3}$, Mohamed Azmi Hassali ${ }^{4}$, Shehla Iftikhar ${ }^{5}$, Mohammad Bashaar*6 and Tafseera Hashemi ${ }^{7}$
}

${ }^{1}$ Faculty of Pharmacy \& Health Sciences, Pakistan

${ }^{2}$ Punjab University College of Pharmacy, Pakistan

${ }^{3}$ Faculty of Pharmacy \& Alternative Medicine, Bahawalpur

${ }^{4}$ School of Pharmaceutical Sciences, Malaysia

${ }^{5}$ Center for Nuclear Medicine and Radiotherapy (CENAR), Pakistan

${ }^{6}$ Health Policy Analyst, SMART Afghan International Trainings \& Consultancy, Afghanistan

${ }^{7}$ Vice Chancellor (Students' Affairs), Afghanistan

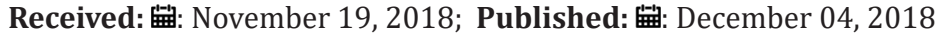

*Corresponding author: Mohammad Bashaar, Health Policy Analyst, SMART Afghan International Trainings \& Consultancy, Kabul, Afghanistan

Abstract

Background: We aimed to assess the Health Literacy (HL) among hypertensive community of Quetta city, Pakistan. Methods: A questionnaire based, cross sectional survey was conducted at Sandeman Provincial Hospital, Quetta. The Health Literacy Questionnaire (HLQ) was used to assess the health literacy level. The cutoff values of having adequate / poor HL were calculated by Receiver Operating Characteristic Curve. Where significant associations were reported, effect size was calculated by using Kendall tau correlation coefficient.

Results: Two hundred and eight five patients responded to the survey with mean age of $45.22 \pm 10.13$ years. Females dominated the cohort $(159,55.8 \%)$, and $78 \%$ of the respondents were married. The scores for the first five domains of HLQ ranged from 11.63 - 15.70. Domain 2 (having sufficient information to manage my health) was significantly associated with educational status $(p=0.005)$ and locality $(p=0.022)$. The appraisal of health information (domain 5) was also significantly associated with educational status ( $p=0.003)$ and locality $(p=0.004)$. Urban respondents had sufficient information about health management and reported better appraisal of health information. Interpretation of significant association among educational status revealed positive moderate correlation $(\tau=0.300$ and 0.436 respectively for domain 2 and 5$)$ whereby respondents with higher education were likely to have sufficient information to manage their health and had better judgment of assessing health-related information. The scores for the remaining four domains ( 6 - 9) ranged from 17.67 - 21.86. All domains (6-9) were significantly associated ( $p<0.05)$ with locality whereas urban respondents having better HL when compared with their counterparts.

Conclusion: Considering the lower HL, a reorientation of the health policy is recommended. Additionally, collaborative efforts must be undertaken by the government, the health care institutions, civil society and mass media to design and implement effectual interventions for improving HL.

Keywords: Health Literacy; Hypertensive Community; Quetta City; Pakistan

Abbreviations: HL: Health Literacy; GDP: Gross Domestic Product; WHO: World Health Organization' ; SPH: Sandeman Provincial Hospital; HLQ: Health Literacy Questionnaire; PHC: Primary Health Centre; BHUs: Basic Health Units; RHCs: Rural Health Centers

\section{Background}

As an emerging concept, the Health Literacy (HL) has been defined as a set of cognitive and social skills that enable individuals to acquire, understand and utilize health-related information [1]. Being an important construct of societal empowerment, HL is not merely the interaction of individuals with the healthcare system but the very concept encapsulates the environmental, political and social factors that affect and determine health and therefore addresses health-related issues [2]. In a broader sense, HL is aimed 
to build the capacity of individuals to attain, communicate, process, and know necessary health information and services to make sound health-related decisions and perform collective actions. Such collective actions enable the individuals to understand factors that influence their health and the approach of addressing them. As a result, adequate levels of HL construct the capabilities where people take responsibility of their own health as well as of the society in large [2]. Being health promotion concept, HL was introduced in 1971 and since then HL has became an essential component of healthcare [3].

HL follows the classic competency model of literacy that access, understand, judge and apply health related information when needed [4]. For that very reason, HL and general literacy are perceived and taken as equivalent to each other. However, this is to remember that being knowledgeable does not guarantee of being skilled in every aspects of life including health. This is evident from literature whereby the Institute of Medicine reported that half of the American adult population had difficulties in assessing and interpreting health-related information [5]. In line to what is reported, 60 and $47 \%$ of the Canadian and European populations were also reported to have limited HL $[6,7]$. The poor levels of HL instigated the need of developing HL guidelines and to adopt a trans-disciplinary approach that was aimed to improve HL [8]. Consequently, in 2004, the American Medical Association developed four key areas of concern: health literacy screening; improving communication with low-literacy patients; costs and outcomes of poor health literacy; and causal pathways of how poor health literacy influences health [9].

Since then, multiple interventions are designed on the proposed framework and have proven effective in term of improving HL [10]. Findings from the developing countries present more drastic figures whereby almost $80 \%$ of adults in Isfahan, Iran had poor HL [11]. A study from Zambia reported $75 \%$ of the female population with limited HL [12]. Similarly, a study conducted in Afghanistan confirms the low level of HL in the country. The study further explores, that besides, lack of health-related knowledge, the individual's attitudes and other cultural factors affect healthcare seeking behavior and act on health-related information and services [13]. Within this context, the situation of HL is not different in Pakistan [14-17]. Multiple reasons are associated with the poor HL in Pakistan. The country's literacy rate declined from 60 to 58\% percent in 2016-17 [18] that is far less to what was proposed by the Sustainable Development Goals [19]. Furthermore, with only 2.1\% of Gross Domestic Product (GDP) spent on education, the spending was lowest in South Asia [20]. In terms of health spending, 0.9\% of GDP was allocated for health [21] while World Health Organization' (WHO) benchmark of health expenditure is at least 6\% [22].

In term of healthcare system performance, healthcare system of Pakistan faces major issues like uncontrolled population growth, lack of maternal education, limited access to quality health care services, urban bias in health services provision, lack of planning, poor management and unnecessary delay in implementation, lack of evaluation process and low utilization of funds and most impotently corruption [23]. Additionally, Pakistan is facing severe lack of human resources whereby the physician-population ratio stands at 1:997, dentist 1:10658 and hospital bed at 1:1584. Unfortunately, there is no data available on the number of pharmacists in the national data base [18]. For these reasons, majority of the population is pushed into 'medical poverty trap', or worst, they do not opt to receive care because of unaffordability [23]. Shifting our concerns to the province of Balochistan, the province is deprived of major facilities including health since independence. Literacy rates are poor as $28 \%$ of its population is literate, with males at $39 \%$ and females at $16 \%$ [24]. When compared with the country, this region is faced with extreme poverty, terrorism, corruption, inflation and unemployment.

Deplorable healthcare is a living dilemma for the local population as majority of the healthcare institutes lack proper infrastructures, have delayed treatment in time and are faced with colossal hygiene problems. Because of all such issues, patients are forced to seek better treatment facilities in other cities of the country [25]. Under such destitute conditions, it is imperative that the patients should be empowered in order to have adequate HL so that they can manage their conditions even in the time of crisis. This becomes crucial where the conditions are chronic in nature and the patients have to manage their conditions for life time. It is now evident that chronic patients with poor HL experience communication difficulties and have limited understanding about medical conditions and treatment, worse health status and increased hospitalization rates are reported. Therefore, understanding of HL might be helpful that can create awareness among patients. For that reason, we aimed to assess the level of HL among hypertensive patients attending a public healthcare institute of Quetta city, Pakistan that will be beneficial in developing practical implications for the patients and the healthcare system.

\section{Methods}

\section{Study Design and Settings}

A questionnaire based, cross sectional survey was conducted. Data was collected from patients attending the cardiac and medicine ward of Sandeman Provincial Hospital (SPH), Quetta. Established in 1939 and located in the center of the city, SPH is a tertiary care, teaching institute. Additionally, being public in nature, SPH is normally the institute of choice for majority of the local residents.

\section{Inclusion Criteria and Sampling Procedure}

Eligible participants were adults aged 18 or over, with an established medical diagnosis of hypertension and using antihypertensive medications for the last six months. We excluded patients with mental disorders and patients seeking assistance in healthcare. Immigrants from other countries were also excluded. For sample size calculation, we used the formula proposed by Daniel and Cross [26]. Hypertension is reported to affect $18 \%$ of the population [27], therefore 228 hypertensive patients $(95 \% \mathrm{Cl}$ and $5 \%$ error) were needed for the study. However, keeping the attrition in mind, a dropout of $20 \%$ was added as proposed in literature [28]. Finally, 273 patients were conveniently targeted for the current study. 


\section{Study Instrument}

In addition to the demographic profile, the Health Literacy Questionnaire (HLQ) was used to assess the health literacy level of the study participants. The HLQ is developed by Osborne et al. [29] by using a grounded, validity-driven approach. The tool has shown strong construct validity, reliability and acceptability to both patients and healthcare providers [30]. The HLQ is a 44-items questionnaire that consists of nine independent domains of health literacy (feeling understood and supported by healthcare providers; having sufficient information to manage my health; actively managing my health; social support for health; appraisal of health information; ability to actively engage with healthcare providers; navigating the healthcare system; ability to find good health information and understand health information enough to know what to do). The scoring algorithm produces unweighted scores for each of the 9 scales of the HLQ. The final score for each scale is an average score across all the questions that form that scale. High scores for each domain reflects improved HL and vice versa.

The HLQ does not provide one overall summative score; rather it gives nine separate scores that indicate a person's strengths and needs in relation to their health literacy [29]. Unlike other tools that assess health literacy based on numeracy skills, reading ability or language comprehension [16,31], the HLQ captures the live experiences of people attempting to understand, access and use health information and health services [29]. Permission to use the HLQ was obtained from the developers (Health Systems Improvement Unit, Deakin University, Melbourne, Australia, HLQ License Agreement L1783IA). The validity and reliability of the HLQ was established through a pilot study with 30 hypertensive patients. All constructs of HLQ reported excellent reliability with an overall alpha value of 0.964 . A focus group was later conducted with the patients that aimed to discuss the acceptability of the constructs. All patients reported ease of reporting and no issues faced during the pilot study ascertaining the validity of HLQ. Data from the pilot study was not included in the actual study.

\section{Statistical Analysis}

The Statistical Package for Social Sciences (version 20.0) was used for data analysis. The HL scores were calculated as proposed by the developers [29]. The cutoff values of having adequate / poor HL were calculated by Receiver Operating Characteristic Curve [32]. The Kolmogrov-Smirnov test was used for normality assessment and non-parametric tests were used accordingly. In addition to the descriptive analysis, dichotomous groups were compared with Mann-Whitney U test. The Jonckheere-Terpstra test was used to evaluate the trend of association. Where significant associations were reported, effect size was calculated by using Kendall tau correlation coefficient. $\mathrm{P}<0.05$ was considered to be of statistical significance.

\section{Ethical Approval}

Departmental ethical committee at Faculty of Pharmacy and Health Sciences, University of Balochistan, Quetta approved the study. In addition, permission was also taken from the Medical Superintendent of SPH. Prior to data collection, the patients were informed about the research initiatives, confidentiality of their responses and their right to withdraw from the study with no penalty or effects on their treatment. Written consent was also taken from the patients.

\section{Discussion}

To assess health literacy among hypertensive community we conducted this study in Quetta city, Pakistan. It is assumed that chronic patients with poor HL lack sufficient self-management knowledge and skills hence resulting in treatment complications and decreased Quality of Life [16]. In addition, patients with poor HL also carry less understanding of the healthcare system. Such patients experience communication difficulties that adversely affect the confidence in receiving the required healthcare hence leading to compromised health outcomes [16]. Lastly, from the perspective of an underprivileged population, poor HL augments the already deprived healthcare system consequently resulting in increased morbidity and mortality. Within this context, assessment of HL can help in developing and implementing HL interventions, which have proven to reduce the burden of both communicable and non-communicable diseases [33].

Results of the current study reported inadequate HL among multiple domains (1, 2, 7, 8 and 9) of HLQ. The satisfactory domains $(3,4,5$ and 6$)$ also had their mean values at the borderline when compared with the calculated cutoff values. Within this context, HL has been evaluated by different researchers through multiple measures in Pakistan. Saeed and colleagues reported inadequate health literacy among diabetic patients in Lahore, Pakistan by using the Short Test of Functional Health Literacy scale [17]. Furthermore, by administrating Health Literacy Survey Questionnaire to adult population in Karachi, Pakistan, Ahmed et al reported that majority of their respondents faced difficulty in finding and understanding health information for their well-being [16]. Similar results were also reported from other studies of the same nature from Pakistan $[15,34]$. Although results of the current study are well aligned with what is reported in literature, our research is the first Pakistanbased study that assessed HL based on the live experiences of the patients. Therefore, being the pioneer study, we were unable to cross refer to literature that assessed HL by using the HLQ in Pakistan.

In addition, the use of HLQ is reported from developed countries; therefore, it is unsound to compare the results between the developed and developing nations because of the societal and psychosocial gap. Nevertheless, as reported in literature and evident from our study result, certain demographic groups are well known to be vulnerable in terms of HL [31] and will be discussed subsequently. We found that respondent with lower education has inadequate HL. The relationship between education and HL has existed for generations and is well defined in literature $[35,36]$. Knesebeck et al in their comparison of twenty two European countries reported that people with low education had poor health and faced functional limitations [37]. In addition, college graduates 
were in better health when compared with people who have not graduated high school [38]. The likelihood of having chronic diseases was also reported to be at the higher sides among the least educated [39]. Where education is critical to social and economical development, the health-related benefits of education are also clearly visible at both micro- and macro levels.

From an individualized perspective (skill development and resource access) to the larger societal and cultural context (healthrelated characteristics of the environment), education improves social policies and residential segregation thatcontributes to positive health outcomes [40]. Additionally, an improved educational status also augments other aspects of HL such as ability to navigate the health care system and addressing disparities in personal health behaviors [40]. Consequently, an advanced educational status is positively linked to improved HL [41,42]. Moreover, educated people carry the tendency to learn more about health and healthrelated hazards that eventually improve their HL and conception of complex issues that are decisive to their wellbeing [43]. There is also evidence that those with higher education have better participation rates in prevention programs [44]. In contrast, people with low education are less likely to be conversant about the health effects. Our claim is supported by literature whereby obese people with poor literacy levels did not see a benefit in losing weight [45].

Summarizing the discussion, a significant effect of education on HL confirms the existence of relationship among the two variables thus supporting the positive trend as reported by the current study. Shifting our concerns to the significant relationship between HL and locality, this association is no way surprising [46,47]. Golboni et al measured inadequate and insignificant rates of HL in the rural areas of Sanandaj, Iran when compared with their counterparts in urban areas [48]. Our findings are further strengthened as rural participants were reported with poor HL in five provinces of Iran [49]. Correlating the literature findings with the current study, poor HL among rural respondents in the current cohort can be attributed to numerous reasons. Among those reasons, the most important is the healthcare situation and structure of Pakistan. In Pakistan, Primary health centre (PHC) units comprise both Basic Health Units (BHUs) and Rural Health Centers (RHCs).The BHUs provide services to around 10,000 people and the RHCs cover around 30,000 to 450,000 people.

However, these centers fail to provide optimal care to the patients because of lack of services, deprived facilities and most importantly the unavailability of the healthcare professionals [27]. Only $33 \%$ of the population has access to health facilities in an area with a $5 \mathrm{~km}$ radius. Therefore, people living in rural areas often have less contact with healthcare professionals which cause poor HL. Furthermore, rural areas are least exposed to health promotion programs such as mass, print and social media in comparison with the people living in urban areas. For those very reasons, it is required to target the rural population to improve their HL for better decision making. Solid and sound decision making and empowerment leads toward improved health behavior and outcomes, while in contrast, low HL causes inadequate treatment adherence, difficulties with managing chronic disease, and ultimately higher healthcare costs [46].

\section{Results}

\section{Demographic Characteristics of the Study Respondents}

Table 1 presents the demographic characteristics of the study respondents. Two hundred and eight five patients responded to the survey with mean age of $45.22 \pm 10.13$ years. Females dominated the cohort $(159,55.8 \%)$, and $78 \%$ of the respondents were married. Thirty percent of the respondents had postgraduate education and $87 \%$ had urban residencies.

Table 1: Demographic characteristics of the study respondents.

\begin{tabular}{|c|c|c|}
\hline Characteristics & Frequency & Percentage \\
\hline \multicolumn{3}{|c|}{ Age $(45.22 \pm 10.13)$ years } \\
\hline $18-27$ & 5 & 1.8 \\
\hline $28-37$ & 55 & 19.3 \\
\hline $38-47$ & 117 & 41.1 \\
\hline$>47$ & 108 & 37.9 \\
\hline \multicolumn{3}{|c|}{ Gender } \\
\hline Female & 159 & 55.8 \\
\hline Male & 126 & 44.2 \\
\hline \multicolumn{3}{|l|}{ Marital status } \\
\hline Married & 224 & 78.6 \\
\hline Unmarried & 61 & 21.4 \\
\hline \multicolumn{3}{|c|}{ Educational status } \\
\hline Primary & 27 & 9.5 \\
\hline Secondary & 44 & 15.4 \\
\hline Higher secondary & 57 & 20.0 \\
\hline Graduate & 71 & 24.9 \\
\hline Post graduate & 86 & 30.2 \\
\hline \multicolumn{3}{|c|}{ Occupational status } \\
\hline Unemployed & 30 & 10.5 \\
\hline House wife & 74 & 26.0 \\
\hline Government employee & 112 & 39.3 \\
\hline Private employ & 38 & 13.3 \\
\hline Businessman / women & 31 & 10.9 \\
\hline \multicolumn{3}{|c|}{ Income (Pakistan rupees = Pk. Rs.) } \\
\hline None & 96 & 33.7 \\
\hline Less than 10000 & 19 & 6.7 \\
\hline $10001-20000$ & 17 & 6.0 \\
\hline $20001-30000$ & 17 & 6.0 \\
\hline$>30000$ & 136 & 47.7 \\
\hline \multicolumn{3}{|l|}{ Locality } \\
\hline Rural & 35 & 12.3 \\
\hline Urban & 250 & 87.7 \\
\hline
\end{tabular}




\section{Health Literacy Profile of the Study Respondents (Domain 1-5)}

Table 2 presents the health literacy profile of the study respondents while focusing on the first five domains. The first five domains provide Likert responses in shape of "strongly disagree" (coded $=1)$, "disagree" (coded $=2$ ), "agree" (coded $=3$ ) and "strongly agree" (coded $=4$ ). Domains 1-2 had maximum score of 16 and minimum of 4 while domains 3-5 had maximum score of 20 and minimum of 5 . The scores for all five domains ranged from 11.63 - 15.70 and based on the cutoff values, the respondents had certain issues in the domain 1 (feeling understood and supported by healthcare providers) followed by domain 2 "having sufficient information to manage my health" as shown in Table 3.

Table 2: Health literacy scores (Domain 1-5).

\begin{tabular}{|c|c|c|c|c|c|c|c|c|c|c|}
\hline \multicolumn{11}{|c|}{ Domain 1: Feeling Understood and Supported by Healthcare Providers } \\
\hline \multirow{2}{*}{ Statements in Health Literacy Questionnaire } & \multicolumn{2}{|c|}{ SD* $^{*}$} & \multicolumn{2}{|c|}{$\mathbf{D}^{*}$} & \multicolumn{2}{|c|}{$A^{*}$} & \multicolumn{2}{|c|}{$\mathbf{S A}^{*}$} & \multirow{2}{*}{ Mean Score } & \multirow{2}{*}{ Cutoff Score } \\
\hline & $\mathbf{N}$ & \%age & $\mathbf{N}$ & \%age & $\mathbf{N}$ & \%age & $\mathbf{N}$ & \%age & & \\
\hline $\begin{array}{l}\text { I have at least one healthcare provider who knows me } \\
\text { well. }\end{array}$ & 11 & 3.9 & 45 & 15.8 & 147 & 51.6 & 82 & 28.8 & \multirow{4}{*}{$12.00 \pm 2.60$} & \multirow{4}{*}{12.50} \\
\hline $\begin{array}{l}\text { I have at least one healthcare provider I can discuss my } \\
\text { health problems with. }\end{array}$ & 17 & 6.0 & 55 & 19.3 & 132 & 46.3 & 81 & 28.4 & & \\
\hline $\begin{array}{l}\text { I have the healthcare providers I need to help me work } \\
\text { out what I need to do. }\end{array}$ & 10 & 3.5 & 57 & 20.0 & 149 & 52.3 & 69 & 24.2 & & \\
\hline I can rely on at least one healthcare provider. & 11 & 3.9 & 49 & 17.2 & 152 & 53.3 & 73 & 25.6 & & \\
\hline \multicolumn{11}{|c|}{ Domain 2: Having Sufficient Information to Manage My Health } \\
\hline I feel I have good information about health. & 9 & 3.2 & 48 & 16.8 & 147 & 51.6 & 81 & 28.4 & \multirow{4}{*}{$11.63 \pm 2.62$} & \multirow{4}{*}{12.50} \\
\hline $\begin{array}{l}\text { I have enough information to help me deal with my } \\
\text { health problems. }\end{array}$ & 15 & 5.3 & 75 & 26.3 & 126 & 44.2 & 69 & 24.2 & & \\
\hline $\begin{array}{l}\text { I am sure I have all the information I need to manage my } \\
\text { health effectively. }\end{array}$ & 18 & 6.3 & 88 & 30.9 & 122 & 42.8 & 57 & 20.0 & & \\
\hline I have all the information I need to look after my health. & 17 & 6.0 & 50 & 17.5 & 151 & 53.0 & 67 & 23.5 & & \\
\hline \multicolumn{11}{|c|}{ Domain 3: Actively Managing My Health } \\
\hline I spend quite a lot of time actively managing my health. & 11 & 3.9 & 85 & 29.8 & 106 & 37.2 & 83 & 29.1 & \multirow{5}{*}{$14.97 \pm 3.18$} & \multirow{5}{*}{14.50} \\
\hline I make plans for what I need to do to be healthy. & 16 & 5.6 & 84 & 29.5 & 107 & 37.5 & 78 & 27.4 & & \\
\hline Despite other things in my life, I make time to be healthy. & 10 & 3.5 & 88 & 30.9 & 111 & 38.9 & 76 & 26.7 & & \\
\hline I set my own goals about health and fitness. & 7 & 2.5 & 31 & 10.9 & 115 & 40.4 & 132 & 46.3 & & \\
\hline $\begin{array}{l}\text { There are things that I do regularly to make myself } \\
\text { healthier. }\end{array}$ & 5 & 1.8 & 71 & 24.9 & 128 & 44.9 & 81 & 28.4 & & \\
\hline \multicolumn{11}{|c|}{ Domain 4: Social Support for Health } \\
\hline $\begin{array}{l}\text { I can get access to several people who understand and } \\
\text { support me. }\end{array}$ & 10 & 3.5 & 37 & 13.0 & 147 & 51.6 & 91 & 31.9 & \multirow{5}{*}{$15.70 \pm 2.95$} & \multirow{5}{*}{14.50} \\
\hline $\begin{array}{l}\text { When I feel ill, the people around me really understand } \\
\text { what I am going through. }\end{array}$ & 21 & 7.4 & 54 & 18.9 & 132 & 46.3 & 78 & 27.4 & & \\
\hline If I need help, I have plenty of people I can rely on. & 14 & 4.9 & 43 & 15.1 & 114 & 40.0 & 114 & 40.0 & & \\
\hline $\begin{array}{l}\text { I have at least one person who can come to medical } \\
\text { appointments with me. }\end{array}$ & 11 & 3.9 & 25 & 8.8 & 136 & 47.7 & 113 & 39.6 & & \\
\hline I have strong support from family or friends. & 5 & 1.8 & 25 & 8.8 & 143 & 50.2 & 112 & 39.3 & & \\
\hline \multicolumn{11}{|c|}{ Domain 5: Appraisal of Health Information } \\
\hline I compare health information from different sources. & 18 & 6.3 & 56 & 19.6 & 134 & 47.0 & 77 & 27.0 & $14.55 \pm 3.42$ & 14.50 \\
\hline $\begin{array}{c}\text { When I see new information about health, I check up on } \\
\text { whether it is true or not. }\end{array}$ & 21 & 7.4 & 88 & 30.9 & 100 & 35.1 & 76 & 26.7 & & \\
\hline $\begin{array}{l}\text { I always compare health information from different } \\
\text { sources and decide what is best for me. }\end{array}$ & 22 & 7.7 & 65 & 22.8 & 118 & 41.4 & 80 & 28.1 & & \\
\hline $\begin{array}{l}\text { I know how to find out if the health information I receive } \\
\text { is right or not. }\end{array}$ & 21 & 7.4 & 73 & 25.6 & 120 & 42.1 & 71 & 24.9 & & \\
\hline $\begin{array}{l}\text { I ask healthcare providers about the quality of the } \\
\text { health information I find. }\end{array}$ & 7 & 2.5 & 51 & 17.9 & 148 & 51.9 & 79 & 27.7 & & \\
\hline
\end{tabular}

Cite this article: Farrukh S, Fahad S, Qaiser I, Naheed H, Sajjad H, Muhammad S, Imran M, Mohamed AH, Shehla I, Mohammad B, Tafseera H. A Cross-Sectional Assessment of Health Literacy among Hypertensive Community of Quetta City, Pakistan. Biomed J Sci \& Tech Res 11(4)-2018. 
Note: * $\mathrm{SD}=$ Strongly disagree, $\mathrm{D}=$ Disagree, $\mathrm{A}=$ Agree, $\mathrm{SA}=$ Strongly agree

Domain 1 = High scores reflect an established relationship with at least one healthcare provider who knows the patients well. Patients who are low on this domain are unable to engage with doctors and other healthcare providers.

Domain 2 = High scores reflect confidence in having information needed to manage diseases and to make decisions. Low scoring patients feel that there are many gaps in their knowledge and that they don't have the information they need to live with and manage their health concerns.

Domain 3 = Patients scoring high recognize the importance of and are able to take responsibility for their own health. People with low levels don't see their health as their responsibility.

Domain 4 = High scores reflect that person's social system provides them with all the support they want or need while low scores indicate completely alone and unsupported.

Domain 5 = High scoring patients are able to identify good information and reliable sources of information. They can resolve conflicting information by themselves or with help from others. Whereas low scoring patients cannot understand most health information and get confused when there is conflicting information.

Table 3: Association analysis (Domain 1-5 and demographic characteristics).

\begin{tabular}{|c|c|c|c|c|c|c|}
\hline \multirow{2}{*}{ Domains (1-5) } & \multicolumn{5}{|c|}{ P-value } & Marital \\
\cline { 2 - 7 } & Age* & Gender** & $\begin{array}{c}\text { Occupational } \\
\text { status* }\end{array}$ & $\begin{array}{c}\text { Educational } \\
\text { status* }\end{array}$ & Income* & Locality** \\
\hline $\begin{array}{c}\text { Domain 1: Feeling understood } \\
\text { and supported by healthcare } \\
\text { providers }\end{array}$ & 0.856 & 0.087 & 0.175 & 0.266 & 0.387 & 0.132 \\
\hline $\begin{array}{c}\text { Domain 2: Having sufficient } \\
\text { information to manage my } \\
\text { health }\end{array}$ & 0.189 & 0.974 & 0.884 & 0.489 & 0.005 & 0.377 \\
\hline $\begin{array}{c}\text { Domain 3: Actively managing } \\
\text { my health }\end{array}$ & 0.751 & 0.826 & 0.490 & 0.220 & 0.220 & 0.335 \\
\hline $\begin{array}{c}\text { Domain 4: Social support for } \\
\text { health }\end{array}$ & 0.686 & 0.586 & 0.232 & 0.636 & 0.512 & 0.426 \\
\hline $\begin{array}{c}\text { Domain 5: Appraisal of health } \\
\text { information }\end{array}$ & 0.100 & 0.502 & 0.112 & 0.445 & 0.003 & 0.130 \\
\hline
\end{tabular}

Note: *Jonckheere-Terpstra test, **Mann Whitney test.

\section{Association Between Health Literacy (Domains 1-5) and Demographic Variables}

The Mann-Whitney and Jonckheere-Terpstra test were used to identify relationship among health literacy domains and demographic variables. Domain 2 (having sufficient information to manage my health) was significantly associated with educational status $(p=0.005)$ and locality $(p=0.022)$. Furthermore, the appraisal of health information (domain 5 ) was also significantly associated with educational status $(\mathrm{p}=0.003)$ and locality $(\mathrm{p}=$ $0.004)$. Urban respondents had sufficient information about health management (mean rank of 144.36 for urban and 133.29 for rural respondents. Furthermore, urban respondents reported to have better appraisal of health information when compared with rural (mean rank of 148.23 and 105.64 respectively). Interpretation of significant association among educational status revealed positive moderate correlation ( $\tau=0.300$ and 0.436 respectively for domain 2 and 5) whereby respondents with higher education were likely to have sufficient information to manage their health and had better judgment of assessing health-related information (Table 4). No significant association was observed among other study variables.

Table 4: Health Literacy scores (Domain 6-9).

\begin{tabular}{|c|c|c|c|c|c|c|c|c|c|c|c|c|}
\hline \multicolumn{13}{|c|}{ Domain 6: Ability to Actively Engage with Healthcare Providers } \\
\hline & \multicolumn{2}{|c|}{$\mathrm{CD} / \mathrm{AD}^{*}$} & \multicolumn{2}{|c|}{ UD* $^{*}$} & \multicolumn{2}{|c|}{ SD* $^{*}$} & \multicolumn{2}{|c|}{ UE* } & \multicolumn{2}{|c|}{$\mathbf{A E}^{*}$} & \multirow{2}{*}{ Mean Score } & \multirow{2}{*}{$\begin{array}{l}\text { Cutoff } \\
\text { score }\end{array}$} \\
\hline & $\mathbf{N}$ & \%age & $\mathbf{N}$ & \%age & $\mathbf{N}$ & \%age & $\mathbf{N}$ & \%age & $\mathbf{N}$ & \%age & & \\
\hline $\begin{array}{l}\text { Make sure that healthcare providers } \\
\text { understand your problems properly. }\end{array}$ & 6 & 2.1 & 31 & 10.9 & 55 & 19.3 & 139 & 48.8 & 54 & 18.9 & \multirow{5}{*}{$18.70 \pm 3.82$} & \multirow{5}{*}{18.50} \\
\hline $\begin{array}{l}\text { Feel able to discuss your health concerns with a } \\
\text { healthcare provider. }\end{array}$ & 8 & 2.8 & 16 & 5.6 & 63 & 22.1 & 139 & 48.8 & 59 & 20.7 & & \\
\hline $\begin{array}{l}\text { Have good discussions about your health with } \\
\text { doctors. }\end{array}$ & 7 & 2.5 & 23 & 8.1 & 55 & 19.3 & 138 & 48.4 & 62 & 21.8 & & \\
\hline $\begin{array}{l}\text { Discuss things with healthcare providers until } \\
\text { you understand all you need to. }\end{array}$ & 4 & 1.4 & 27 & 9.5 & 79 & 27.7 & 129 & 45.3 & 46 & 16.1 & & \\
\hline $\begin{array}{l}\text { Ask healthcare providers questions to get the } \\
\text { health information you need. }\end{array}$ & 11 & 3.9 & 22 & 7.7 & 60 & 21.1 & 124 & 43.5 & 68 & 23.9 & & \\
\hline
\end{tabular}




\begin{tabular}{|c|c|c|c|c|c|c|c|c|c|c|c|c|}
\hline \multicolumn{13}{|c|}{ Domain 7: Navigating the Healthcare System } \\
\hline Find the right health care. & 31 & 10.9 & 97 & 34.0 & 0 & 0 & 125 & 43.9 & 32 & 11.2 & \multirow{6}{*}{$21.86 \pm 4.13$} & \multirow{6}{*}{22.50} \\
\hline Get to see the healthcare providers you need to. & 5 & 1.8 & 24 & 8.4 & 71 & 24.9 & 126 & 44.2 & 59 & 20.7 & & \\
\hline $\begin{array}{c}\text { Decide which healthcare provider you need to } \\
\text { see. }\end{array}$ & 7 & 2.5 & 28 & 9.8 & 65 & 22.8 & 110 & 38.6 & 75 & 26.3 & & \\
\hline $\begin{array}{l}\text { Make sure you find the right place to get the } \\
\text { health care you need. }\end{array}$ & 9 & 3.2 & 21 & 7.4 & 102 & 35.8 & 100 & 35.1 & 53 & 18.6 & & \\
\hline $\begin{array}{l}\text { Find out which healthcare services you are } \\
\text { entitled to. }\end{array}$ & 8 & 2.8 & 37 & 13.0 & 105 & 36.8 & 93 & 32.6 & 42 & 14.7 & & \\
\hline Work out what the best care is for you. & 4 & 1.4 & 23 & 8.1 & 58 & 20.4 & 145 & 50.9 & 55 & 19.3 & & \\
\hline \multicolumn{13}{|c|}{ Domain 8: Ability to Find Good Health Information } \\
\hline Find information about health problems. & 12 & 4.2 & 29 & 10.2 & 105 & 36.8 & 95 & 33.3 & 44 & 15.4 & \multirow{5}{*}{$17.67 \pm 4.18$} & \multirow{5}{*}{18.50} \\
\hline $\begin{array}{l}\text { Find health information from several different } \\
\text { places. }\end{array}$ & 18 & 6.3 & 33 & 11.6 & 87 & 30.5 & 106 & 37.2 & 41 & 14.4 & & \\
\hline $\begin{array}{l}\text { Get information about health so you are up to } \\
\text { date with the best information. }\end{array}$ & 21 & 7.4 & 29 & 10.2 & 83 & 29.1 & 103 & 36.1 & 49 & 17.2 & & \\
\hline $\begin{array}{l}\text { Get health information in words you } \\
\text { understand. }\end{array}$ & 13 & 4.6 & 23 & 8.1 & 59 & 20.7 & 134 & 47.0 & 56 & 19.6 & & \\
\hline Get health information by yourself. & 10 & 3.5 & 31 & 10.9 & 61 & 21.4 & 130 & 45.6 & 53 & 18.6 & & \\
\hline \multicolumn{13}{|c|}{ Domain 9: Understand Health Information Well Enough to Know What to Do } \\
\hline $\begin{array}{l}\text { Confidently fill medical forms in the correct } \\
\text { way. }\end{array}$ & 22 & 7.7 & 27 & 9.5 & 76 & 26.7 & 91 & 31.9 & 69 & 24.2 & \multirow{2}{*}{$18.17 \pm 3.98$} & \multirow{2}{*}{18.50} \\
\hline $\begin{array}{l}\text { Accurately follow the instructions from } \\
\text { healthcare providers. }\end{array}$ & 3 & 1.1 & 23 & 8.1 & 60 & 21.1 & 142 & 49.8 & 57 & 20.0 & & \\
\hline $\begin{array}{l}\text { Read and understand written health } \\
\text { information. }\end{array}$ & 15 & 5.3 & 30 & 10.5 & 68 & 23.9 & 113 & 39.6 & 59 & 20.7 & & \\
\hline $\begin{array}{l}\text { Read and understand all the information on } \\
\text { medication labels. }\end{array}$ & 19 & 6.7 & 25 & 8.8 & 88 & 30.9 & 97 & 34.0 & 56 & 19.6 & & \\
\hline $\begin{array}{l}\text { Understand what healthcare providers are } \\
\text { asking you to do. }\end{array}$ & 6 & 2.1 & 31 & 10.9 & 56 & 19.6 & 139 & 48.8 & 53 & 18.6 & & \\
\hline
\end{tabular}

Note: $\quad * \mathrm{CD} / \mathrm{AD}=$ cannot do or always difficult, $\mathrm{UD}=$ usually difficult, $\mathrm{SD}=$ sometimes difficult, $\mathrm{UE}=\mathrm{usually}$ easy, $\mathrm{AE}=$ always easy

Domain 6 = Patients scoring high are proactive about their health and feels in control in relationships with healthcare providers. Low scoring patients are passive in their approach to health care and do not proactively seek or clarify information and advice and/or service options.

Domain 7 = High scoring patients can find out about services and supports so they get all their needs met. On the contrary, low scoring patients do not look beyond obvious resources and have a limited understanding of what is available.

Domain $8=$ High scorers actively use a diverse range of sources to find information. Low scoring patients cannot access health information when required.

Domain 9 = Patients with high scores are able to understand all written information (including numerical information) in relation to their health. Patients with low scores have problems understanding any written health information or instructions about treatments or medications.

\section{Health Literacy Profile of the Study Respondents (Domain 6-9)}

Table 5 presents the health literacy profile of the study respondents while focusing on the remaining four domains i.e. 6-9. All these domains provide Likert responses in shape of "cannot do or always difficult" ( $\operatorname{coded}=1$ ), "usually difficult" ( $\operatorname{coded}=2$ ), "sometimes difficult" (coded = 3) "usually easy" (coded =4) and "always easy" (coded =5). Domains 6, 8 and 9 had maximum score of 25 and minimum of 5 whereas domain 7 had maximum score of 30 and minimum of 6 . The scores for all four domains ranged from
17.67 - 21.86. The respondents had certain issues in the domain 7, 8 and 9 (Table 5).

\section{Association Between Health Literacy (Domains 6-9) and Demographic Variables}

All domains $(6-9)$ were significantly associated $(\mathrm{p}<0.05)$ with locality whereas the mean rank interpretation revealed urban respondents having better literacy when compared with the respondents from the rural areas. No significant association was reported among other study variables as shown in Table 5. 
Table 5: Association analysis (Domain 6-9 and demographic characteristics).

\begin{tabular}{|c|c|c|c|c|c|c|c|}
\hline \multirow[b]{2}{*}{ Domains (6-9) } & \multicolumn{7}{|c|}{ P-value } \\
\hline & Age* $^{*}$ & Gender $^{* *}$ & $\begin{array}{l}\text { Marital } \\
\text { status** }\end{array}$ & $\begin{array}{l}\text { Occupational } \\
\text { status* }\end{array}$ & $\begin{array}{c}\text { Educational } \\
\text { status* }\end{array}$ & Income* & Locality $^{* *}$ \\
\hline $\begin{array}{c}\text { Domain 6: Ability to actively engage with } \\
\text { healthcare providers }\end{array}$ & 0.913 & 0.891 & 0.533 & 0.132 & 0.398 & 0.255 & 0.023 \\
\hline $\begin{array}{c}\text { Domain 7: Navigating the healthcare } \\
\text { system }\end{array}$ & 0.612 & 0.687 & 0.065 & 0.261 & 0.550 & 0.611 & 0.034 \\
\hline $\begin{array}{l}\text { Domain 8: Ability to find good health } \\
\text { information }\end{array}$ & 0.607 & 0.442 & 0.146 & 0.557 & 0.880 & 0.766 & 0.009 \\
\hline $\begin{array}{l}\text { Domain 9: Understand health information } \\
\text { well enough to know what to do }\end{array}$ & 0.190 & 0.968 & 0.337 & 0.833 & 0.361 & 0.276 & 0.002 \\
\hline
\end{tabular}

Note: *Jonckheere-Terpstra test, **Mann Whitney test.

\section{Conclusion}

Our respondents with lower educational status and belonging to the rural residencies reported low HL. Considering the lower HL among our study respondents, a reorientation of the health policy is recommended. Health literacy as a determinant for health and social welfare should be focused with more details and must be taken up as a priority. Additionally, collaborative efforts must be undertaken by the government, the health care institutions, civil society and mass media to design and implement effectual interventions for improving HL.

\section{Acknowledgement}

Kerrie Paulger, Health Systems Improvement Unit, Deakin University, Melbourne for providing the HLQ and giving the continuous feedback through questionnaire piloting till data analysis. We would like to acknowledge the patients and paramedical staff of SPH, Quetta for their cooperation during the data collection process.

\section{Funding}

This research received no specific grant from any funding agency in the public, commercial or not-for-profit sectors.

\section{Availability of Data and Materials}

All data generated or analyzed during this study are included in this article. However, the datasets of the current study available from the corresponding author on reasonable request.

\section{Authors' Contributions}

FS carried out the study design and execution of the research work and writing of the initial draft of the manuscript. FS, QI, NH, $\mathrm{SH}, \mathrm{MS}$ and IM assist in writing and expert review of the manuscript. MAH, SI, MB and TH reviewed the statistical analysis for appropriate writing of the manuscript and expert review of the manuscript. All authors read and approved the final version of the manuscript.

\section{Ethics Approval and Consent to Participate}

Departmental ethical committee at Faculty of Pharmacy and Health Sciences, University of Balochistan, Quetta approved the study. In addition, permission was also taken from the Medical Superintendent of SPH.

\section{References}

1. Health promotion.

2. Nutbeam D (2000) Health literacy as a public health goal: a challenge for contemporary health education and communication strategies into the 21st century. Health Promotion International 15(3): 259-267.

3. Simonds SK (1974) Health education as social policy. Health Education Monographs 2: 1-25.

4. Logan RA, Siegel ER (2017) Health Literacy: New Directions in Research, Theory and Practice. Amsterdam, Netherlands: IOS Press.

5. (2004) Institute of Medicine: Health literacy: a prescription to end confusion. Nielsen Bohlman L, Panzer AM, Kindig DA (Eds.) Washington DC: The National Academies.

6. Rootman I, Gordon-El-Bihbety D (2008) A vision for a health literate Canada. Ottawa, ON: Canadian Public Health Association.

7. Nakayama K, Osaka W, Togari T, Ishikawa H, Yonekura Y, et al. (2015) Comprehensive health literacy in Japan is lower than in Europe: a validated Japanese-language assessment of health literacy. BMC Public Health 15(1): 505.

8. Lloyd LLJ, Ammary NJ, Epstein LG, Johnson R, Rhee K (2006) A transdisciplinary approach to improve health literacy and reduce disparities. Health Promot Pract 7(3): 331-335.

9. Mc Cray AT (2005) Promoting health literacy. Journal of the American Medical Informatics Association 12(2): 152-163.

10. Malik M, Zaidi RZ, Hussain R (2017) Health Literacy as a global public health concern: a systematic review. Journal of Pharmacology \& Clinical Research 4(2): 1-6.

11. Javadzade SH, Sharifirad G, Radjati F, Mostafavi F, Reisi M, et al. (2012) Relationship between health literacy, health status, and healthy behaviors among older adults in Isfahan, Iran. J Educ Health Promot 1: 31.

12. Schrauben SJ, Wiebe DJ (2015) Health literacy assessment in developing countries: a case study in Zambia. Health promotion international 32(3): 475-481.

13. Harsch S (2017) Health literacy in crisis-affected Afghanistan: a quantitative study on beliefs and barriers Stefanie Harsch. European Journal of Public Health 27(1).

14. Sabzwari SR (2017) Health literacy in Pakistan: Exploring new ways of addressing an old challenge. The J Pak Med Assoc 67(12): 1901-1904.

15. Saleem F, Hashmi F, Atif N, Bukhari N, Ahsan M, et al. (2015) A Cross Sectional Assessment of Health Literacy among Cardiovascular Patients in Karachi, Pakistan. Health Economics and Outcome Research 1(101): 2 . 
16. Ahmed W, Shaikh ZN, Soomro JA, Qazi HA, Soomro AK (2018) Assessment of health literacy in adult population of Karachi: a preliminary investigation for concept-based evidence. International Journal of Health Promotion and Education p. 1-9.

17. Saeed H, Saleem Z, Naeem R, Shahzadi I, Islam M (2018) Impact of health literacy on diabetes outcomes: a cross-sectional study from Lahore, Pakistan. Public Health 156: 8-14.

18. (2016-17) Pakistan Economic Survey.

19. (2015) Millennium Development Goals (MDGs).

20. (2016) Pakistan's education spending lowest in South Asia.

21. (2018) Health expenditure, public (\% of GDP).

22. (2003) How much should countries spend on health?

23. (2018) Poor health facilities.

24. Rehman A, Jingdong L, Hussain I (2015) The province-wise literacy rate in Pakistan and its impact on the economy. Pacific Science Review B: Humanities and Social Sciences 1(3): 140-144.

25. (2016) Poor healthcare in Balochistan.

26. Daniel WW, Cross CL (2010) Biostatistics: basic concepts and methodology for the health sciences: John Wiley \& Sons New York, USA.

27. Saleem F, Hassali AA, Shafie AA (2010) Hypertension in Pakistan: time to take some serious action. British Journal of General Practice 60(575): 449-450.

28. Field A (2013) Discovering statistics using IBM SPSS statistics.Sage, London, UK.

29. Osborne RH, Batterham RW, Elsworth GR, Hawkins M, Buchbinder R (2013) The grounded psychometric development and initial validation of the Health Literacy Questionnaire (HLQ). BMC Public health 13(1): 658.

30. Hawkins M, Gill SD, Batterham R, Elsworth GR, Osborne RH (2017) The Health Literacy Questionnaire (HLQ) at the patient-clinician interface: a qualitative study of what patients and clinicians mean by their HLQ scores. BMC Health Services Research 17(1): 309.

31. Beauchamp A, Buchbinder R, Dodson S, Batterham RW, Elsworth GR, et al. (2015) Distribution of health literacy strengths and weaknesses across socio-demographic groups: a cross-sectional survey using the Health Literacy Questionnaire (HLQ). BMC Public Health 15(1): 678.

32. Hajian Tilaki K (2013) Receiver Operating Characteristic (ROC) Curve analysis for medical diagnostic test evaluation. Caspian Journal of Internal Medicine 4(2): 627-635.

33. Sheridan SL, Halpern DJ, Viera AJ, Berkman ND, Donahue KE, et al. (2011) Interventions for individuals with low health literacy: a systematic review. Journal of Health Communication 16(sup3): 30-54.

34. Suhail K (2005) A study investigating mental health literacy in Pakistan. Journal of Mental Health 14(2): 167-181.

ISSN: 2574-1241

DOI: 10.26717/BJSTR.2018.11.002141

Mohammad Bashaar. Biomed J Sci \& Tech Res

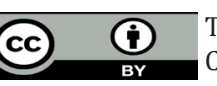

This work is licensed under Creative Commons Attribution 4.0 License

Submission Link: https://biomedres.us/submit-manuscript.php
35. Berkman ND, Sheridan SL, Donahue KE, Halpern DJ, Crotty K (2011) Low health literacy and health outcomes: an updated systematic review. Ann Intern Med 155(2): 97-107.

36. (2006) What are the effects of education on health.

37. Von dem Knesebeck O, Verde PE, Dragano N (2006) Education and health in 22 European countries. Social Science \& Medicine 63(5): 1344-1351.

38. Olshansky SJ, Antonucci T, Berkman L, Binstock RH, Boersch Supan A, et al. (2012) Differences in life expectancy due to race and educational differences are widening, and many may not catch up. Health Affairs 31(8): 1803-1813.

39. Goldman D, Smith JP (2011) The increasing value of education to health. Social Science \& Medicine 72(10): 1728-1737.

40. Zimmerman E, Woolf SH (2014) Understanding the relationship between education and health. In: Population Health: Behavioral and Social Science Insights. (edn.) Edited by Robert M. Kaplan, Michael L Spittel, Daryn H David Rockville (Eds), Institute of Medicine of the National Academies.

41. Adams RJ (2010) Improving health outcomes with better patient understanding and education. Risk Management and Healthcare Policy 3: 61-72.

42. Schillinger D, Barton LR, Karter AJ, Wang F, Adler N (2006) Does literacy mediate the relationship between education and health outcomes? A study of a low-income population with diabetes. Public Health Reports 121(3): 245-254.

43. Pampel FC, Krueger PM, Denney JT (2010) Socioeconomic disparities in health behaviors. Annual Review of Sociology 36: 349-370.

44. Sabates R, Feinstein L (2006) The role of education in the uptake of preventative health care: the case of cervical screening in Britain. Social Science \& Medicine 62(12): 2998-3010.

45. Kennen EM, Davis TC, Huang J, Yu H, Carden D, et al. (2005) Tipping the scales: The effect of literacy on obese patients' knowledge and readiness to lose weight. Southern Medical Journal 98(1): 15-18.

46. Zahnd WE, Scaife SL, Francis ML (2009) Health literacy skills in rural and urban populations. American Journal of Health Behavior 33(5): 550-557.

47. Pop OM, Brînzaniuc A, Şirlincan EO, Baba CO, Cherecheş RM (2013) Assessing health literacy in rural settings: A pilot study in rural areas of Cluj County, Romania. Global Health Promotion 20(4): 35-43.

48. Golboni F, Nadrian H, Najafi S, Shirzadi S, Mahmoodi H (2017) Urbanrural differences in health literacy and its determinants in Iran: A community-based study. Aust J Rural Health 26(2): 98-105.

49. Banihashemi S AT, Amirkhani MA, AliAkbar H, Seyed MA, Homa A, et al. (2007) Health literacy and the influencing factors: a study in five provinces of Iran. Studies in Development of Medical Education 4: 1-9.

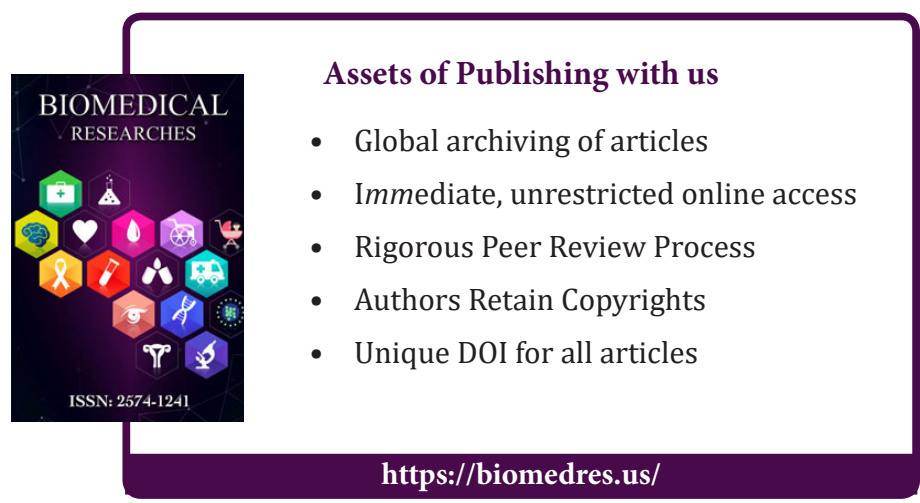

Cite this article: Farrukh S, Fahad S, Qaiser I, Naheed H, Sajjad H, Muhammad S, Imran M, Mohamed AH, Shehla I, Mohammad B, Tafseera H. A Cross-Sectional Assessment of Health Literacy among Hypertensive Community of Quetta City, Pakistan. Biomed J Sci \& Tech Res 11(4)-2018. BJSTR. MS.ID.002141. DOI: 10.26717/ BJSTR.2018.11.002141. 